\title{
Laser-diffraction and pipette-method grain sizing of Dutch sediments: correlations for fine fractions of marine, fluvial, and loess samples
}

\author{
P. Buurman ${ }^{\star}$,Th. Pape, J. A. Reijneveld ${ }^{1}$, F. de Jong and E. van Gelder \\ Laboratory of Soil Science and Geology, Department of Environmental Sciences, \\ Wageningen University, P.O. Box 37, 6700 AA Wageningen, The Netherlands \\ * corresponding author. E-mail: peter.buurman@bodeco.beng.wau.nl \\ 1 Present address: Plant Research International, P.O. Box 16, 6700 AA Wageningen, \\ The Netherlands
}

Manuscript received: November 1999; accepted in revised form January 2001

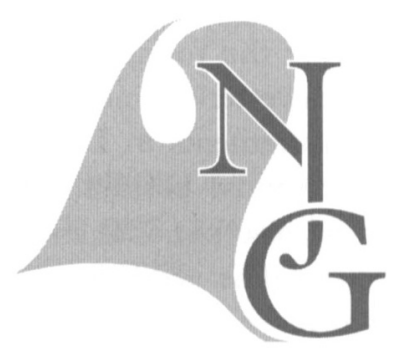

\begin{abstract}
To evaluate correlations between silt and clay fractions determined by pipette method and laser diffraction, samples from Dutch fine marine, fluvial, and loess deposits were analysed by both methods. For fluvial deposits, correlations for fractions $<2$ and $>50 \mu \mathrm{m}$ were excellent $\left(R^{2}>0.95\right)$, those for $2-4,4-8,16-32$ and $32-50 \mu \mathrm{m}$ were satisfactory $\left(R^{2}=0.80-0.95\right)$, while that for the fraction $8-16 \mu \mathrm{m}$ had an $\mathrm{R}^{2}$ of only 0.68 . For marine deposits, correlations for $<2$ and $>50 \mu \mathrm{m}$ were in the same range, but those of all other fractions except 8-16 $\mu \mathrm{m}$ were lower. In the loess samples, correlations for all but the 8-16 $\mu \mathrm{m}$ fraction were unsatisfactory. Laser diffraction gave $42 \%$ of pipette clay in marine samples, and $62 \%$ in fluvial and loess samples if regressions are forced through 0 . Sand fractions detected by laser diffraction were $107 \%$ of the sieve fraction in marine samples, and $99 \%$ in the fluvial samples. Correlations for fractions smaller than reference size are generally better than those for individual size fractions. Both the $2 \mu \mathrm{m}$ and the $50 \mu \mathrm{m}$ boundary cause problems in the comparison. The first because of platy shape of clay minerals, and the second due to both a change in method in the pipette/sieving procedure, and to nonsphericity of particles. Apparently, correlations for clay- and silt-size fractions obtained by pipette method and laser diffraction will be different for each type of sediment.
\end{abstract}

Key words: clay fraction, fluvial sediments, grain size distribution, laser diffraction, loess sediments, marine sediments, pipette method, silt fraction.

\section{Introduction}

Although laser diffraction is a rapid and well-documented method for grain-size analysis of soils and sediments, differences with the classical and certified sieve and pipette method in the amounts of fine fractions, notably fractions $<2 \mu \mathrm{m}$, are a major inhibition to the universal use of laser diffraction.

Pipette analysis, which is based on settling velocity of spherical particles, is used to determine fractions $<2,<4,<8,<16,<32$, and $<50 \mu \mathrm{m}$, from which data the separate fractions $(2-4,4-8$, etc.) are calculated.

Laser-diffraction instruments have different ranges of measurement, and use different numbers of detectors to cover this range. The Fritsch A22 uses 31 de- tectors and measures the size range 0.16-1250 $\mu \mathrm{m}$; the Malvern Master Sizer E uses 32 detectors and has a size range of $0.1-600 \mu \mathrm{m}$; the Coulter LS100 has 72 detectors and a range of 0.4 to $900 \mu \mathrm{m}$, and the Coulter LS230 uses 116 diffraction detectors and an additional 6 for polarized light to measure the extremely fine fractions, and has a range of $0.04-2000 \mu \mathrm{m}$.

The number of detectors corresponds with the effectively measured fractions (each detector measures the central range of the fraction it represents). Although the output data allow the used to determine percentages of fractions between any two chosen grain sizes that are not boundaries dictated by the detector angles, such percentages are based on interpolations. The accuracy of the distribution obtained de- 
pends therefore on the number of detectors used for a specific size-range. For instruments with different size-ranges and numbers of detectors, the relation between measurement and interpolation is necessarily different, and because of the different number of detectors for the fine size fractions and the use of polarization intensity in some instruments, it is to be expected that measurements in the fine fraction will be different. This is illustrated by different correlations between pipette- and laser-diffraction clay contents as published by various authors using laser diffraction. Van Dongen (1989, in Konert \& Vandenberghe, 1997), who analysed fluvial and lacustrine sediments with a Malvern Master Sizer, found less than $20 \%$ of pipette clay. McCave et al (1986) found similar amounts with the Malvern 3600E, and Konert and Vandenberghe (1997) found roughly 36\%, using a Fritsch A22 and a range of different sediment samples. Muggler et al. (1997) found about $50 \%$ of pipette clay for Brazilian Oxisols using a Coulter LS230. Problems concerning the comparison of pipette and laser diffraction methods have been discussed in detail by Loiseau et al. (1994), Müller and Schuhmann (1996), Buurman et al. (1997), and Konert and Vandenberghe (1997). The work of Buurman et al. (1997) and Muggler et al. (1997), which was carried out at our laboratory, showed that the relation between the two measurements may change within one soil profile. In the analysed soil profiles, the clay minerals changed from the saprolite upwards from fairly large pseudomorphs of kaolinite after mica to fine-grained kaolinite. This suggested that the relation between pipette clay and laser-diffraction clay may depend on properties of the clay fraction itself.

To compensate for the so-called underestimate of the clay fraction by laser diffraction, Konert and Vandenberghe (1997) suggested using the laser-diffraction fraction of $<8 \mu \mathrm{m}$ as a proxy for pipette fraction $<2$ $\mu \mathrm{m}$. This approach has two major disadvantages. First, it considers the pipette method as a reference for the percentage of clay particles, although it is known (and also substantiated by their own calculations) that it will contain platy particles of significantly larger size. This overestimation of the clay fraction by sedimentation method is mentioned in most publications on this method (e.g. Loveland and Whalley, 1991). Secondly, because some laser diffraction instruments do actually measure a number of fractions in the $<2$ and $2-8 \mu \mathrm{m}$ size ranges. The Coulter LS230 measures 42 classes between 0.04 and $2.01 \mu \mathrm{m}$ and 16 classes between 2.01 and $8.147 \mu \mathrm{m}$. Dumping the latter 16 classes with the clay fraction would negate the fact that many particles in the $2-8 \mu \mathrm{m}$ range are not platy, and are therefore not detected incorrectly.

A so-called 'underestimate' of the clay fraction by laser diffraction (with respect to the differently biased pipette method) must automatically result in 'overestimating' of one or more coarser fractions, because the sum of fractions remains $100 \%$. Should the measurements of the sand fraction by sieving and laserdiffraction, be compatible, as is ascertained by various authors (see below), the compensation should occur between 2 and $50 \mu \mathrm{m}$. This can only be verified by detailed measurement of silt fractions by both pipette method and laser diffraction.

Correlation between laser-diffraction and sieving for sand-sized fractions is usually good (Loizeau et al., 1994; Zonneveld, 1994), although laser diffraction of sediments tends to give slightly coarser mean grain-sizes than sieve analysis. This can be attributed to non-sphericity of sediment particles (Konert and Vandenberghe, 1997).

Working with samples from Dutch soils and sediments, we got the impression that, correlations between amounts of fine fractions measured by laser diffraction and by pipette method may be influenced by, in addition to mineralogy (different falling speed of particles of different density), the size distribution within the fine fractions. Therefore, the correlation may change with sediment type.

Because laser diffraction provides more information and is far more efficient that the pipette-sieve method, while the latter is an accepted and certified method, it is essential to know whether a universal correlation exists between fine fractions obtained by both methods. We decided to analyse sediments and soils of different origin, compare in detail the results obtained by the two grain-size analysis methods. Measurement of the clay-size fraction by laser diffraction usually results in smaller percentages than those obtained by pipette method. Sand-size particles are measured more or less equally by both methods. This means that the lower percentages of the clay fraction measured by laser diffraction must be compensated by higher percentages in the silt-size fraction. We intended to determine in which size range the 'underestimate' of the clay fraction is compensated. Because the correlations for sand-size fractions are well documented and not problematic, we have concentrated on the finer fractions.

\section{Materials and methods}

We used three sets of samples of different origin:

1. Recent marine sediments from the province of 
Zeeland, the Netherlands (54 samples), supplemented, for the fraction $<2 \mu \mathrm{m}$, by 19 samples from various similar deposits from the provinces of North and South Holland.

2. 39 samples of recent fluviatile sediments from the Betuwe area, province of Gelderland, the Netherlands

3. 45 loess samples from a sequence in the Brulsch quarry and neighbouring locations, province of Limburg.

Samples were chosen to represent a maximum range in pipette-clay content. Because the aeolian loess samples are very homogeneous in grain-size distribution, the range in clay content in these samples is much smaller than in the other two sets.

Before grain-size analysis, all samples were sieved over a $2 \mathrm{~mm}$ sieve. The fraction $<2 \mathrm{~mm}$ was used for further analysis. To avoid artefacts, calcium carbonate and organic matter were removed from all samples according to standard procedures (Van Doesburg, 1996). For pipette-sieve analysis, $20 \mathrm{~g}$ samples were used. The fractions $<2,<4,<8,<16,<32$ and $<50 \mu \mathrm{m}$ were obtained by pipetting, the fraction $>50 \mu \mathrm{m}$ by sieving. Sand fractions were not further subdivided.

For laser diffraction, representative samples of $1 \mathrm{~g}<2$ $\mathrm{mm}$ received the same pretreatment as the fractions for pipette-sieve analysis. The pre-treated suspension was fully transferred to the measuring cuvette of the laser apparatus. If necessary, the sample was diluted to the required obscuration of $10 \%$ as described by Pape (1996) and Buurman et al. (1997). Because all samples are relatively fine, this dilution does not create changes in the distribution of coarse fractions.

Measurements were carried out with a Coulter LS230 apparatus. This instrument measures 116 grain-size classes in the range of $0.04-2000 \mu \mathrm{m}$. The lower size class boundary is $0.04 \mu \mathrm{m}$, and each following boundary is 1.098 times the preceding one. The apparatus uses the Mie theory (see e.g. Müller and Schuhmann, 1996) to calculate grain-sizes from the intensity of the diffracted light. Constants were 1.33 for the refractive index of water, 1.56 for the refractive index of the solid phase (valid for quartz, clay minerals and feldspars), and adsorption coefficients of 0.15 for the $750 \mathrm{~nm}$ laser and 0.20 for the three polarized wavelengths (Buurman et al., 1997). The latter values were based on adsorption measurements on a number of natural and deferrated samples at sediment concentration as used in the laser diffraction. Calculations included the PIDS measurement. However, at an obscuration of $10 \%$ as used in the measurements, the adsorption values for the polarized wavelength have little influence on the calculation of fractions.

To obtain laser-diffraction fractions similar to those of the pipette method, nearest fraction boundaries were chosen, and the fractions $<2(2.01),<4(4.24)$, $<8(8.147),<16(15.65),<32(33),<50(52.63)$ and $>50(52.63) \mu \mathrm{m}$, were read from the distribution curves.

Correlations were calculated for all size fractions $(<2,2-4, \ldots>50)$ obtained by the two methods, and for the summed fractions smaller than reference value $(<2,<4 \ldots<50)$. Two types of correlations were used: (1) the best linear correlation, and (2) a linear correlation forced through 0 , because zero contents give zero values in both methods. Regression formulas and $R^{2}$ values were determined.

\section{Results}

The ranges in size distributions of the various sample sets are given in Figure 1. The coarsest sample of the
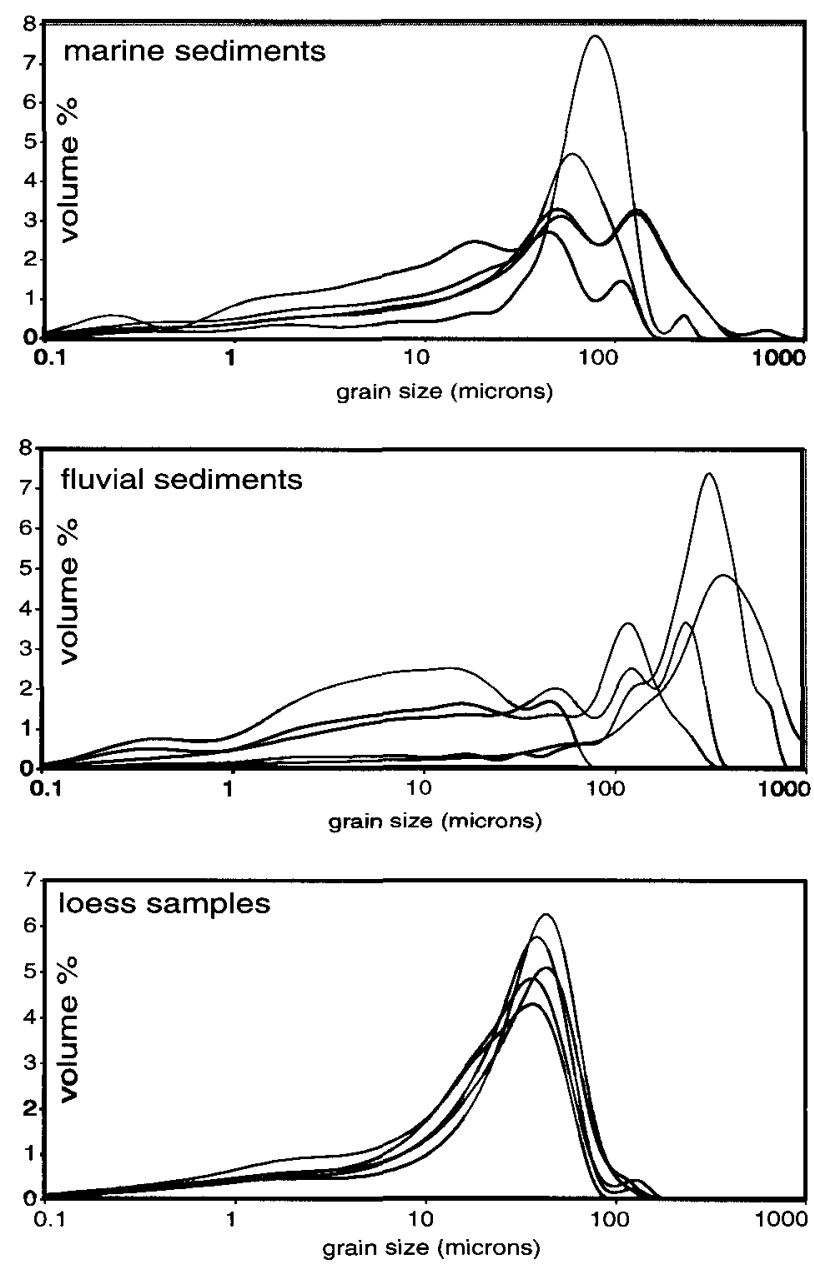

Figure 1. Examples of laser-diffraction grain-size distribution curves of marine, fluvial, and loess samples. For clarity, all distributions have been cut off at 0.1 and $1000 \mu \mathrm{m}$ (the measurement range was $0.04-2000 \mu \mathrm{m}$ ). 

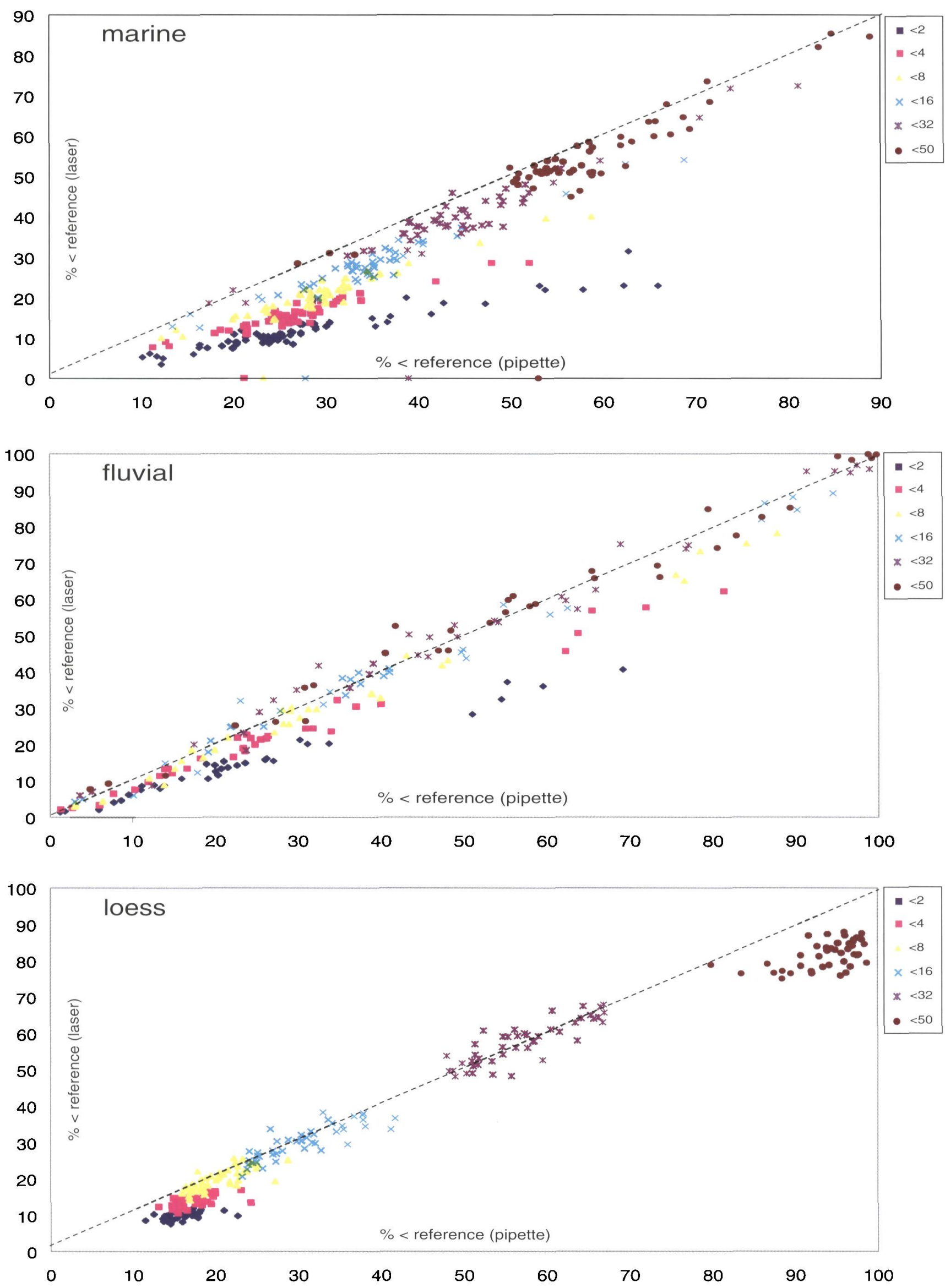

Figure 2. Comparison of cumulative values in pipette method and laser-diffraction. 

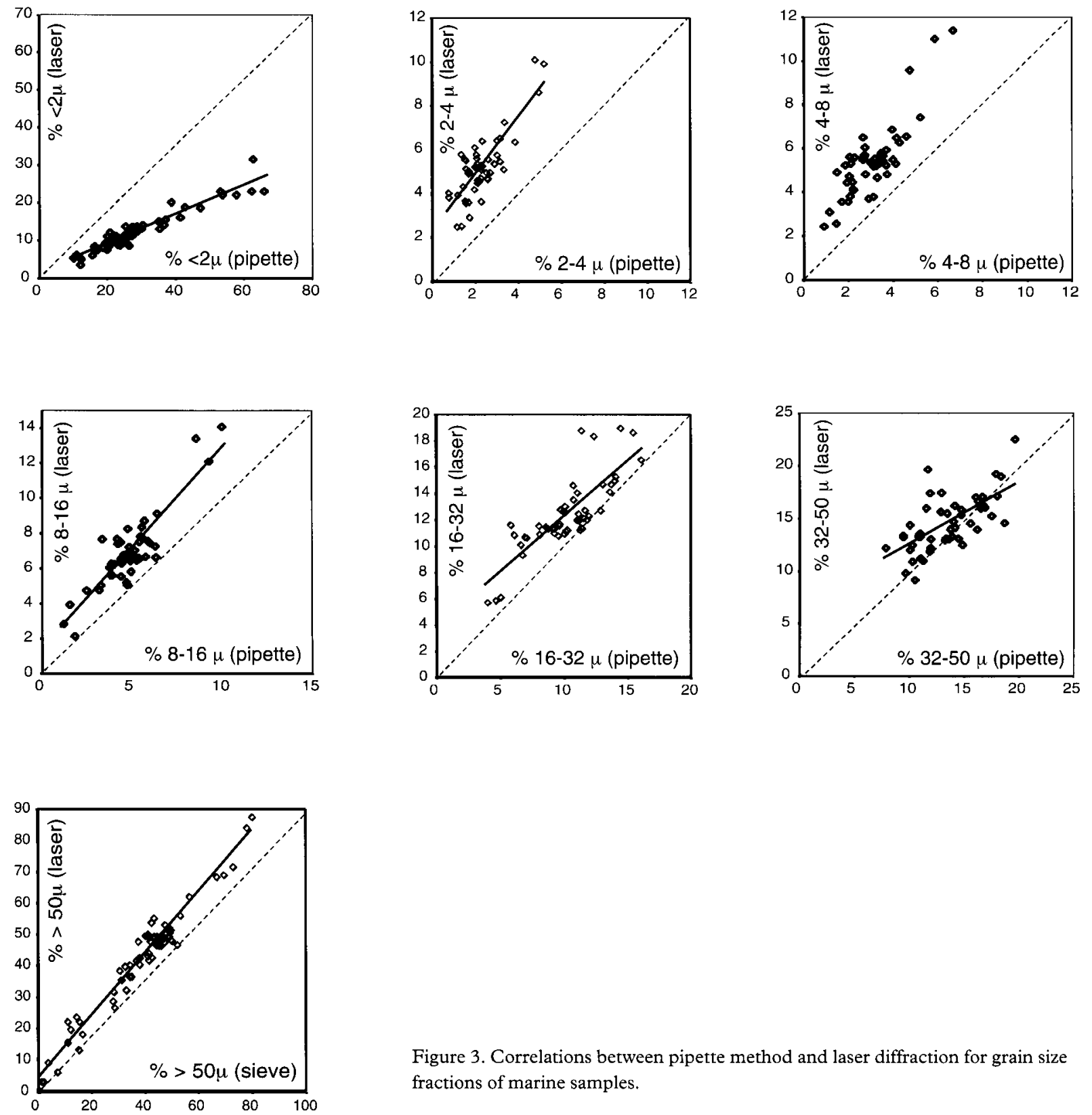

Figure 3. Correlations between pipette method and laser diffraction for grain size fractions of marine samples.

fluvial sediments contains a fraction 1000-2000 $\mu \mathrm{m}$, but the axis was cut at $1000 \mu \mathrm{m}$ to facilitate comparison between the sediment groups. The homogeneity of the loess samples is obvious.

All correlations are reported in Table 1 . Good correlation was obtained for the clay size fraction of the marine and fluvial sediments, but the conversion factor of laser-clay to pipette-clay was different for the two sets. The regressions were:

Marine sediments:

$$
\begin{array}{ll}
\text { Clay }_{\text {laser }}=0.39 \text { Clay }_{\text {pipette }}+1.03 & \mathrm{R}^{2}=0.91 \\
\text { Clay }_{\text {laser }}=0.42 \times \text { Clay }_{\text {piperte }} & \mathbf{R}^{2}=0.90
\end{array}
$$

Fluvial sediments:

$$
\begin{array}{ll}
\text { Clay }_{\text {laser }}=0.60 \times \text { Clay }_{\text {pipette }}+0.73 & \mathrm{R}^{2}=0.98 \\
\text { Clay }_{\text {laser }}=0.62 \times \text { Clay }_{\text {pipette }} & \mathrm{R}^{2}=0.98
\end{array}
$$

Loess sediments:

$$
\begin{array}{ll}
\text { Clay }_{\text {laser }}=0.29 \times \text { Clay }_{\text {pipette }}+5.16 & \mathrm{R}^{2}=0.62 \\
\text { Clay }_{\text {laser }}=0.62 \times \text { Clay }_{\text {piperte }} & \mathrm{R}^{2}=0.32
\end{array}
$$

The low correlation for the loess sediments is mainly due to the narrow range in clay contents $(11-23 \%$ pipette clay), which increases the influences of analytical error.

Comparing fractions smaller than a reference val- 
Table 1. Correlations between pipette and laser-diffraction size fractions for marine, fluvial and loess sediments.

\begin{tabular}{|c|c|c|c|c|c|}
\hline Size class $(\mu \mathrm{m})$ & Correlation (1) & $\mathrm{r}^{2}$ & Correlation (2) & $\mathrm{r}^{2}$ & range (\%) \\
\hline \multicolumn{6}{|l|}{ Marine } \\
\hline$<2$ & $y=0.39 x+1.03$ & 0.91 & $y=0.42 x$ & 0.90 & $10-70$ \\
\hline $2-4$ & $y=1.29 x+2.23$ & 0.67 & $y=2.11 x$ & 0.34 & $0-6$ \\
\hline $4-8$ & $y=1.23 x+1.69$ & 0.70 & $y=1.72 x$ & 0.57 & $0-6$ \\
\hline $8-16$ & $y=1.16 x+1.28$ & 0.79 & $\mathrm{y}=1.39 \mathrm{x}$ & 0.76 & $0-10$ \\
\hline $16-32$ & $y=0.84 x+3.74$ & 0.67 & $y=1.18 x$ & 0.55 & $4-16$ \\
\hline $32-50$ & $y=0.59 x+8.55$ & 0.43 & $\mathrm{y}=1.06 \mathrm{x}$ & 0.15 & $7-20$ \\
\hline$>50$ & $y=1.00 x+3.34$ & 0.96 & $y=1.07 x$ & 0.96 & $0-80$ \\
\hline$<4$ & $y=0.58 x+0.01$ & 0.79 & & & \\
\hline$<8$ & $y=0.72 x-0.48$ & 0.82 & & & \\
\hline$<16$ & $y=0.82 x-0.76$ & 0.82 & & & \\
\hline$<32$ & $y=0.91 x-1.04$ & 0.77 & & & \\
\hline$<50$ & $y=0.99 x-3.65$ & 0.67 & & & \\
\hline \multicolumn{6}{|l|}{ Fluvial } \\
\hline$<2$ & $y=0.60 x+0.73$ & 0.98 & $y=0.62 x$ & 0.98 & $0-70$ \\
\hline $2-4$ & $y=1.61 x+0.93$ & 0.94 & $y=1.74 x$ & 0.93 & $0-8$ \\
\hline $4-8$ & $y=1.29 x+0.64$ & 0.85 & $\mathrm{y}=1.38 \mathrm{x}$ & 0.85 & $0-11$ \\
\hline $8-16$ & $y=1.03 x+1.89$ & 0.68 & $\mathrm{y}=1.24 \mathrm{x}$ & 0.65 & $0-14$ \\
\hline $16-32$ & $y=0.93 x+2.20$ & 0.92 & $y=1.12 x$ & 0.87 & $0-22$ \\
\hline $32-50$ & $y=0.72 x+1.92$ & 0.88 & $\mathrm{y}=0.90 \mathrm{x}$ & 0.81 & $0-15$ \\
\hline$>50$ & $y=0.97 x+1.16$ & 0.98 & $y=0.99 x$ & 0.98 & $0-95$ \\
\hline$<4$ & $y=0.78 x+1.04$ & 0.98 & & & \\
\hline$<8$ & $y=0.88 x+1.15$ & 0.99 & & & \\
\hline$<16$ & $y=0.94 x+1.73$ & 0.98 & & & \\
\hline$<32$ & $y=0.96 x+2.60$ & 0.98 & & & \\
\hline$<50$ & $y=0.96 x+2.68$ & 0.98 & & & \\
\hline \multicolumn{6}{|l|}{ Loess } \\
\hline$<2$ & $y=0.29 x+5.16$ & 0.32 & $y=0.62 x$ & neg & $11-23$ \\
\hline $2-4$ & $y=0.71 x+3.07$ & 0.22 & $\mathrm{y}=2.60 \mathrm{x}$ & neg & $0-3$ \\
\hline $4-8$ & $y=0.85 x+3.35$ & 0.72 & $y=1.76 x$ & neg & $1-6$ \\
\hline $8-16$ & $\mathrm{y}=0.81 \mathrm{x}+2.24$ & 0.81 & $y=1.02 x$ & 0.74 & $6-15$ \\
\hline $16-32$ & $\mathrm{y}=0.31 \mathrm{x}+19.0$ & 0.22 & $\mathrm{y}=1.01 \mathrm{x}$ & neg & $20-33$ \\
\hline $32-50$ & $y=0.28 x+13.9$ & 0.26 & $y=0.65 x$ & neg & $28-46$ \\
\hline$>50$ & $y=0.48 x+15.5$ & 0.28 & $\mathrm{y}=2.24 \mathrm{x}$ & neg & $0-20$ \\
\hline$<4$ & $y=0.46 x+6.05$ & 0.34 & & & \\
\hline$<8$ & $y=0.70 x+5.65$ & 0.55 & & & \\
\hline$<16$ & $y=0.78 x+6.50$ & 0.71 & & & \\
\hline$<32$ & $y=0.84 x+9.37$ & 0.72 & & & \\
\hline$<50$ & $y=0.48 x+36.9$ & 0.28 & & & \\
\hline
\end{tabular}

$\mathrm{y}=$ fraction measured by laser diffraction; $\mathrm{x}=$ fraction measured by pipette/sieving.

Correlation (2) is forced through 0 .

ue, for the three types of sediments (Figure 2a-c), it turns out that in the marine clays, the cumulative values for all laser-diffraction size-fractions are below those of the pipette method. Only a few samples of the $<16,<32$, and $<50$ fractions are on the $1: 1$ line. With increasing upper limit, the cumulative values are closer to this line, but the low values for the clay contents are not fully compensated by higher values in silt fractions. This can only be explained by an overestimate of the silt fraction in the sieve/pipette analysis due to non-sphericity of coarse silt grains.

In fluvial sediments (Figure 2b), the low laser values for clay contents are compensated by the fractions between 2 and $16 \mu \mathrm{m}$. The cumulative values of the fractions $<16 \mu \mathrm{m}$, and also of the fractions $<32$ and $<50$, are on the 1:1 line. This different behaviour from the marine sediment is in line with the fact that fluvial sediments usually have more spherical grains than marine ones.

In the loess samples (Figure 2c), the cumulative values of the fractions $<16$ and $<32 \mu \mathrm{m}$ are on the $1: 1$ line, while the fraction $<8 \mu \mathrm{m}$ is only slightly below it. Remarkable is the deviation of the $<50 \mu \mathrm{m}$ fraction, which is systematically lower in laser diffraction. In the sieve-pipette method, this fraction boundary is al- 

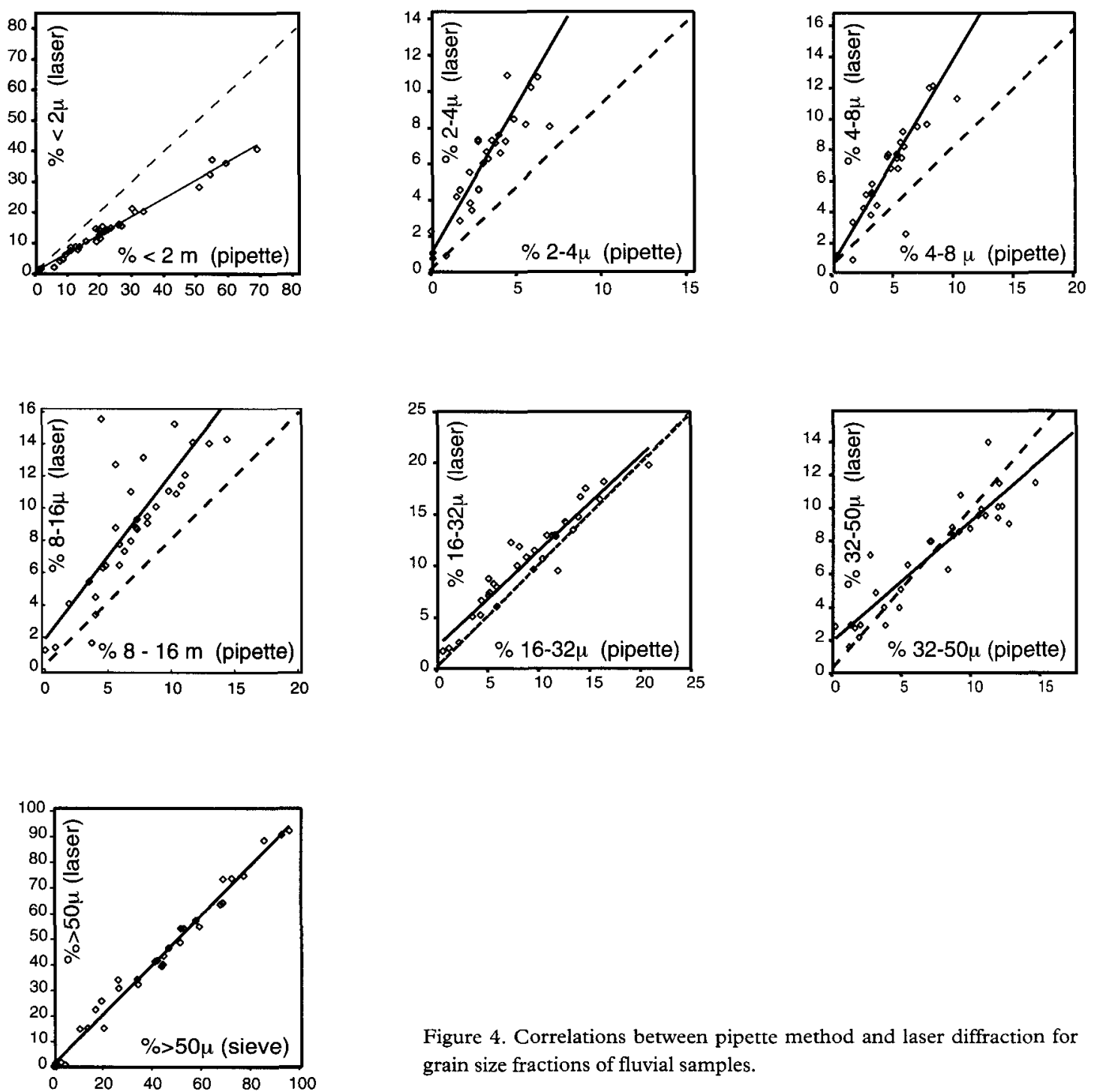

Figure 4. Correlations between pipette method and laser diffraction for grain size fractions of fluvial samples.

so the boundary between two methods of determination: sieving above $50 \mu \mathrm{m}$, and pipette method below. If the maximum of the grain-size distribution is close to $50 \mu \mathrm{m}$, both sieving and pipette method are prone to large errors; the first if grains are not spherical, the second because of rapid sedimentation of such large particles. Figure 1 indicates that in loess samples the maximum of the size-distribution is indeed close to $50 \mu \mathrm{m}$.

Examining correlations for the different size fractions (Table 1, Figure 3-5), we should keep in mind that in some cases the weight percent of the fraction considered has very low values or a very narrow range (Table 1) and is therefore due to relatively large errors.

In addition, the correlations are only valid for the range of percentages in the investigated samples and cannot always be extrapolated to zero. The latter is especially valid for loess samples, where the correlations that are not forced through zero have a large cut-off on the Y-axis.

In the marine samples, all laser fractions between 2 and $50 \mu \mathrm{m}$ are systematically higher than the pipette fractions. Correlations are fairly poor, with $\mathrm{R}^{2}$ values between 0.43 and 0.79 . With increasing grain size, the relation in the correlations forced through zero is closer to unity $(2.12,1.72,1.39,1.18$, and 1.06 , respectively for the fractions $2-4,4-8,8-16,16-32$, and 32-50. Worst correlations are found for the $32-50 \mu \mathrm{m}$ fraction, which may again be due to the transition between two methods of measurement, but some authors attribute this to the presence of biogenic opal in marine sediments (McCave et al., 1995; Clemens and Prell, 1990). Such opal particles have a lower specific density than mineral grains and do not follow Stokes' law because of their irregular shape. Correlation for the fraction $>50 \mu \mathrm{m}$ is close to unity and very good $\left(r^{2}=0.96\right)$. 

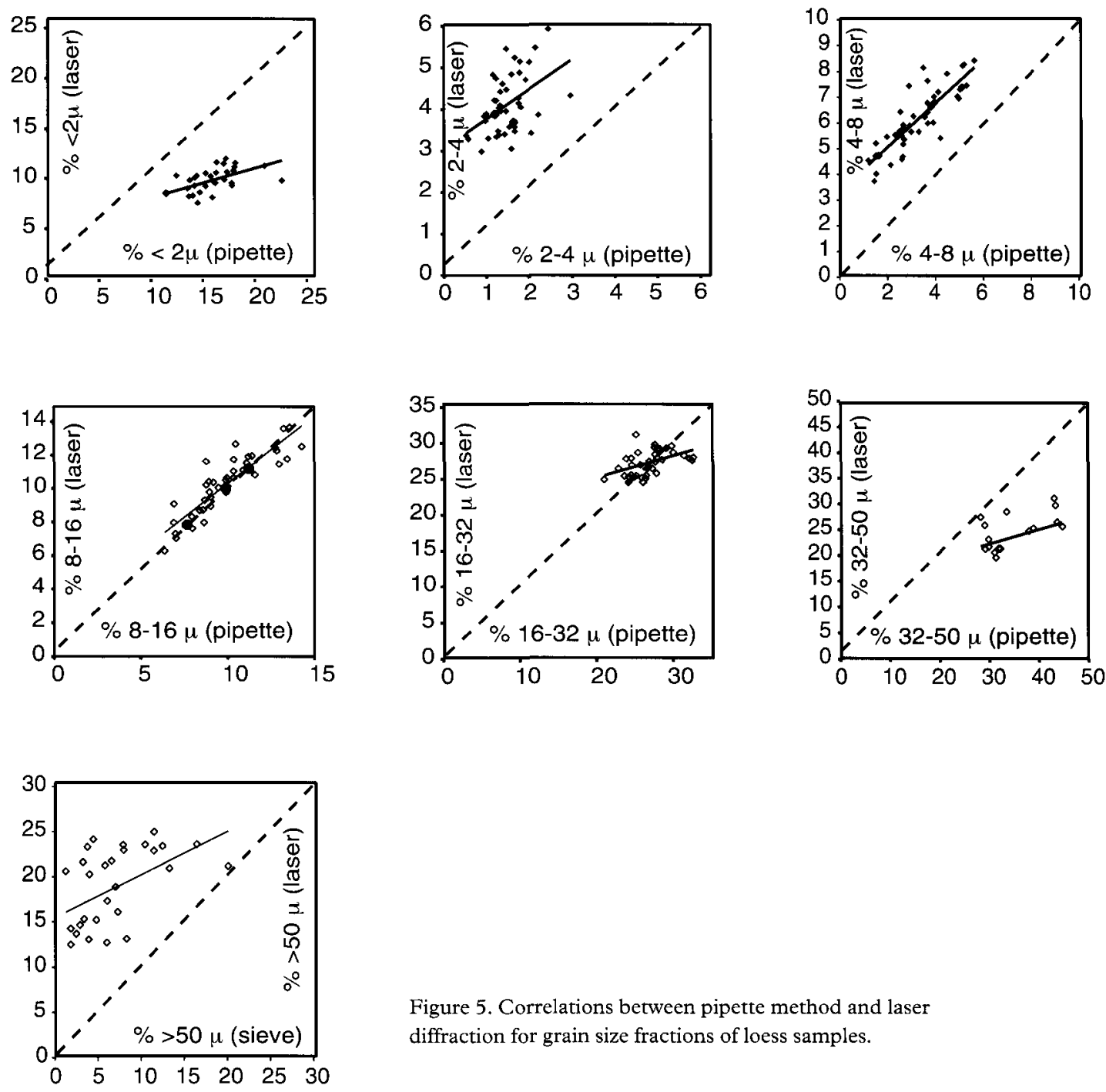

Figure 5. Correlations between pipette method and laser diffraction for grain size fractions of loess samples.

A largely similar picture, but with much better correlations, is found for fluvial samples (Figure 4). The laser-fractions $2-4,4-8,8-16$, and 16-32 $\mu \mathrm{m}$ are systematically higher than the pipette fractions. Correlation for $2-4 \mu \mathrm{m}$ is very good $\left(\mathrm{r}^{2}=0.94\right)$. Correlation for fraction $4-8 \mu \mathrm{m}$ is still satisfactory $\left(r^{2}=0.85\right)$, but that for $8-16 \mu \mathrm{m}$ is worse $\left(r^{2}=0.68\right)$, while those for $16-32$ and $32-50 \mu \mathrm{m}$ are again satisfactory $\left(\mathrm{r}^{2}=0.92\right.$ and 0.88 , respectively). The correlations forced through zero are not much lower. Correlation for the sand fraction is virtually equal to unity, and has a very high $\mathbf{r}^{2}(0.98)$.

In the loess samples, grain-size distributions are fairly uniform. Correlations in general are not very good (Figure 5). Regressions have very poor $\mathrm{R}^{2}$ values, except for the fractions $4-8$ and 8-16 $\mu \mathrm{m}(0.72$ and 0.81 ), while the regressions forced through zero are even worse. Because the laser and pipette fractions
$<50 \mu \mathrm{m}$ deviate considerably, a poor correlation is also found for the fraction $>50 \mu \mathrm{m}$. As mentioned before, this can be ascribed to both non-sphericity of particles and to the transition between two methods of measurement in sieve/pipette analysis.

For both marine and fluvial data sets, correlation is improved considerably when fractions smaller than a reference value are compared (Table 1, italicised). These correlations were calculated for the data points in Figure 2, but not shown in this figure to maintain clarity. Especially in the fluvial data set, this leads to almost perfect correlations. In both the marine and the loess data set, the problems around the $50 \mathrm{~mm}$ boundary are still evident.

\section{Discussion}

Relations between pipette- and laser-diffraction grain-size fractions are different for the three types of sediments. This holds true for both the 'under-esti- 
mation' of the clay-size fraction by laser-diffraction (or the over-estimation by pipette method), and for the size fraction for which a relation of unity is reached. The fact that both in marine and in loess samples, laser fractions $<50 \mu \mathrm{m}$ are smaller than the sieve/pipette fractions, is mainly due to non-sphericity of grains. In general, correlations for loess are less than satisfactory and should be investigated further.

When comparing pipette- and laser diffraction results, one should keep in mind that the principles of measurement are different, and that both methods do not address the problem of platy particles. In the pipette methods this leads to an overestimate of platy particles and of any particles (e.g. biogenic opal) that have a lower apparent density than the standard used for the estimate of settling velocity. For laser diffraction, Muller and Schuhmann (1996) stated that: '... non-spherical particles are wrongly detected, but the obtained 'wrong' distribution of intensities is subsequently calculated correctly.'

This means that in most cases, it is better to use the methods separately. Because laser diffraction is a superior method, both in ease of measurement and in amount of information obtained, this method will generally be chosen for scientific research.

In cases where a correlation between pipette- and laser diffraction clay percentages is required, using a larger grain-size in laser diffraction to obtain a $1: 1$ correlation with pipette clay is only a partially satisfactory solution, because it assumes that the fraction of 2-8 $\mu \mathrm{m}$ consists of platy particles and is detected wrongly in laser diffraction. In many samples the 'real' fraction 2-8 microns will consist of both platy and non-platy particles, while in other samples it does not contain any platy minerals. It is therefore more desirable, as also defended by Konert and Vandenberghe (1997) to obtain the correct correlation for each type of sediment, however tedious this may be.

\section{Acknowledgements}

We used 19 samples of marine clays analysed by Mrs. Heidi Smit for her MSc thesis. The financial support of Coulter Electronics Nederland (now Beckman Coulter) to Mr Reijneveld, Mr De Jong, and Mr Van Gelder is gratefully acknowledged.

\section{References}

Buurman, P., Pape, Th. \& Muggler, C.C., 1997. Laser grain-size determination in soil genetic studies 1. Practical problems. Soil Science, 162: 211-218.

Clemens, S.C., \& Prell, W.L., 1990. Late Pleistocene variability of Arabian Sea summer monsoon winds and continental aridity: aeolian records from the lithogenic component of deep-sea sediments. Paleoceanography, 5:109-145.

Konert, M. \& Vandenberghe, J., 1997. Comparison of laser grain size analysis with pipette and sieve analysis: a solution for the underestimation of the clay fraction. Sedimentology, 44:523-535.

Loizeau, J.L., Arbouille, D., Santiago, S. \& Vernet, J.P., 1994. Evaluation of a wide-range laser diffraction grain-size analyser for use with sediments. Sedimentology, 41:353-361.

Loveland, P.G. \& Whalley, W.R., 1991. Particle size analysis. In: Smith, K.A. \&Mullins, C.E. (eds).Soil Analysis - Physical Methods. Marcel Dekker (New York): 271-328.

McCave, I.N., Bryant, R.J., Cook, H.F., \& Coughanowr, C.A., 1986. Evaluation of a laser diffraction size analyser for use with natural sediments. Journal of Sedimentary Petrology, 56:561564.

McCave, I.N., Manighetti, B., \& Robinson, S.G., 1995. Sortable silt and fine sediment size/composition slicing: parameters for paleo-current speed and paleoceanography. Paleoceanography, 10:593-610

Muggler, C.C., Pape, Th. \& Buurman, P., 1997. Laser grain-size determination in soil genetic studies 2 . Clay content, clay formation, and aggregation in some Brazilian Oxisols. Soil Science, 162:219-228.

Müller, R.H. \& Schuhmann, R., 1996. Teilchengrössenmessung in der Laborapraxis. Wissenschafliche Verlagsgesellschaft $\mathrm{mbH}$ (Stuttgart): 191pp.

Pape, Th, 1996. Sample preparation for grain-size determination by laser diffraction. In: Buurman, P., Van Lagen, B. \& Velthorst, E.J. (eds.): Manual for Soil and Water Analysis. Backhuys Publishers (Leiden): 287-290.

Van Doesburg, J.D.J., 1996. Particle-size analysis and mineralogical analysis. In: Buurman, P., Van Lagen, B. \& Velthorst, E.J.(eds.): Manual for Soil and Water Analysis. Backhuys Publishers (Leiden): 251-278

Zonneveld, P.C., 1994. Comparative investigation of grain-size determination (sieve/Malvern). Report No. OP 6500, State Geological Survey, Haarlem, The Netherlands. 